\title{
Stock Assessment of Albacore, Thunnus alalunga, in the Indian Ocean by Surplus Production Models with a New Relative Abundance Index
}

\author{
Hsiang-Wen Huang ${ }^{1}$, Chien-Chung Hsu ${ }^{2, *}$, Hui-Hua Lee ${ }^{2}$, and Yu-Min Yeh ${ }^{2}$
}

(Manuscript received 14 March 2003, in final form 30 April 2003)

\begin{abstract}
Albacore (Thunnus alalunga), harvested mainly by longline, has been productive in the Indian Ocean, The population dynamics of Indian albacore has been analyzed by various assessing models. However, the abundance index used previously showed variety within some extents to result in uncertain measures for the stock status. With respect to the importance of environmental factors in estimating an abundance index, the objectives of the present paper are to standardize catch per unit effort for Taiwanese Iongline fishery by involving a sea surface temperature in general linear model, and to assess the albacore stock using the estimated abundance index by surplus production models. The results obtained reveal that the standardized catch per unit effort follows closely the fishery and the maximum sustainable yield estimated ranges from 32,168 to 34,910 metric tons and effective fishing effort at maximum sustainable yield ranges from 296 to 313 million standardized hooks for different surplus production models. Therefore, the stock status is evaluated to be in healthy and fully exploited condition; and a close monitoring, still, an intensive analysis using age-structured models is recommended for subsequent studies.
\end{abstract}

(Key words: Albacore (Thunnus alalunga), Catch per unit effort, General linear models, Abundance index, Surplus production model)

\section{INTRODUCTION}

Albacore (Thunnus alalunga) is a highly migratory and economically important species, distributed in tropical and temperate waters of all oceans and the Mediterranean Sea between $45^{\circ} \mathrm{N}$ and $40^{\circ} \mathrm{S}$ but not at the surface waters between $10^{\circ} \mathrm{N}$ and $10^{\circ} \mathrm{S}$. It is abundant in the waters with a sea surface temperature from 15.6 to $19.4^{\circ} \mathrm{C}$, and from 13.5 to $25.2^{\circ} \mathrm{C}$ for the large adult albacore in particular (Collette and Nauen 1983).

\footnotetext{
${ }^{1}$ Fisheries Administration, Council of Agriculture, Taipei, Taiwan, ROC

${ }^{2}$ Institute of Oceanography, National Taiwan University, Taipei, Taiwan, ROC

*Corresponding author: Prof. Chien-Chung Hsu, Institute of Oceanography, National

Taiwan University, Taipei, 106, Taiwan, ROC; E-mail: hsucc@ccms.ntu.edu.tw
} 
In the Indian Ocean, albacore are distributed between 15 to $45^{\circ} \mathrm{S}$, and were traditionally caught by longline and surface gears. Since the 1970s, the annual production of albacore taken by those fisheries ranges from 10,000 metric tons to 40,000 metric tons. About $60 \%$ to $90 \%$ of that production was made by Taiwanese fisheries from year to year (Anon. 2000).

Using standardized catch per unit effort (CPUE) as the abundance index, the Indian albacore stock has been assessed by production models (cf. Huang et al. 1986; Shiohama 1988; Chang 1993; Hsu 1995), a yield per recruit analysis with uncertain life parameters (Chang et al. 2001), virtual population analysis (Lee and Liu 1995) and recently by a fuzzy production model (Wang et al. 2001a, b). Those studies indicate that the stock is likely in the status of healthy and full exploitation. However, one of the disadvantages for those population dynamics analyses is the high variety of available abundance indices, represented by the standardized CPUE.

The high variety of the standardized CPUE results from two sources: one is that the catch/ effort data used include various information of different fishing types (Lin 1998), and the other is that the environmental factor, which is evidenced as an important factor for tuna distribution (Hinton and Nakano 1996; Marsac 2001; Okamoto et al. 2001), has not been used in the standardization of abundance indices. Incorporation of the environmental factor into the analysis may yield a better representative of abundance index (Hinton and Nakano 1996). Therefore, the objectives of this study are to incorporate the sea surface temperature into the general linear model to improve the reliability of the standardized CPUE for albacore stock in the Indian Ocean, and to use this new relative abundance index to reevaluate the stock status of the albacore by surplus production models.

\section{MATERIALS AND METHODS}

\subsection{Catch and Effort Data}

The catch and effort data used in the present study were collected from the daily logbooks of Taiwanese distant-waters tuna longline fleets from 1979 to 1998. These data were taken on a daily $5 \times 5$-degree squared basis by vessels, including fishing dates, locations of deployment, number of hooks between floats (available since 1995), daily deployed hooks and catches in number and in weight of albacore, bigeye tuna (T. obesus), yellowfin tuna (T. albacares), bluefin tuna (T. thynnus), southern bluefin tuna (T. maccoyii), swordfish (Xiphias gladius), and billfishes etc.

Those effort data may include two fishing types, i.e., the regular and the deep longline fishing types. In general, these two different longline fishing types were used to target different species. Prior to standardization, the separation of these two fishing types is necessary, because the CPUE derived from combining two fishing types is always biased (Lin 1998). Hence, the collected catch and effort data are reviewed, and daily deployed longline sets for different targets of albacore were segregated in accordance with the criteria provided by Lin (1998). 


\subsection{Sea Surface Temperature Data}

Monthly mean sea surface temperature (SST) was derived from the Advanced Very High Resolution Radiometer (AVHRR) carried aboard the NOAA-series polar-orbiting satellites. These data were downloading from NASA's web site from 1979 to 1998.

The original SST data is recorded on a monthly $1 \times 1$-degree squared basis. Therefore, 25 data in a 5x5-degree squared block were averaged. And the average SST in each 5x5-degree squared block was incorporated into each corresponding $5 \times 5$-degree squared catch and effort data item. Because albacore is mainly distributed in the waters of 15.6 to $25.2^{\circ} \mathrm{C}$ (Collette and Nauen 1983), SSTs higher than $28^{\circ} \mathrm{C}$ or lower than $16^{\circ} \mathrm{C}$ were excluded in the analysis.

\subsection{General Linear Models}

Based on the analysis of estimating fishing power by Robson (1966), general linear models (GLM) were first used by Francis (1974) in standardized CPUE as the representative of a fish stock abundance index, while Allen and Punsly (1984), Punsly (1987) and O'Brien and Kell (1997) have described in detail the method used for tuna stock. In this study, the nominal CPUE was calculated as catch in number of fish per 1,000 hooks. Then, a basic GLM model could be expressed by

$$
\ln \left(C P U E_{i j k l}+\text { constant }\right)=\mu+Y_{i}+M_{j}+A_{k}+S_{l}+M_{j} x A_{k}+\varepsilon_{i j k l},
$$

where $\mu$ : Overall mean; constant: $10 \%$ of overall mean of nominal CPUEs; $Y_{i}$ : effect of year $i ; M_{j}$ : effect of temporal factor $j ; A_{k}$ : effect of spatial factor $k ; S_{l}$ : effect of SST $l ; M_{j} x A_{k}$ : interaction of month and area; and $\varepsilon_{i j k l}$ : error term with $\mathrm{N}\left(0, \sigma^{2}\right)$.

Factors of year, month and area were selected as main effects, and the two-way interaction between month and area was considered. The SST was incorporated as an environmental factor. To investigate the effect of individual factor on the full model, 6 combinations (Table 1) were used to evaluate the estimation of standardized CPUE.

Based on the distribution of average CPUE from 1979 to 1998, the sub-area was stratified as Fig. 1 depicted. Approximately similar nominal CPUEs around its 5x5-degree squared neighborhoods were confronted into the similar sub-area, then; the fishing area was divided into 7 and 5 sub-areas.

The temporal factor was classified in two ways. In Models 1-3, the factor was presented as monthly basis, and in Models 4-6, four seasons (January to March, April to June, July to September, and October to December) were used.

To avoid the difficulty of classifying annual effect from interaction between year factor and other factors, only the interaction between season and sub-area interaction was used in models 1-6, and an additional interaction between season and SST was used in model 6. Also, the zero nominal CPUE could not be calculated with logarithmic transformation, a 10\% of the overall mean of nominal CPUE is usually added as the constant (Uojumi 1993; Campbell et al. 1996) in the GLM analysis.

The best model was selected by Akaike's Information Criterion (AIC, Akaike 1973; 1976; 
Table 1. The combinations of factors used in the general linear models to standardize catch per unit effort of albacore stock in the Indian Ocean for Taiwanese longline fisheries, in which the figures in the parentheses are numbers of category used in the factors.

Model Formula

\begin{tabular}{|c|c|}
\hline 1 & $\begin{array}{l}\ln (\text { CPUE }+0.1 \text { meanCPUE })=\text { Year }(20)+\operatorname{Area}(7)+\text { Month }(12)+ \\
\text { Area*Month }\end{array}$ \\
\hline 2 & $\begin{array}{l}\ln (\text { CPUE }+0.1 \text { meanCPUE })=\text { Year }(20)+\text { Area }(7)+\text { Month }(12)+S S T \\
\left(13,16^{\circ} \mathrm{C}-28^{\circ} \mathrm{C}\right)+\text { Area*Month }\end{array}$ \\
\hline 3 & $\begin{array}{l}\ln (C P U E+0.1 \text { meanCPUE })=\text { Year }(20)+\operatorname{Area}(4)+\text { Month }(12)+ \\
\operatorname{SST}\left(13,16^{\circ} \mathrm{C}-28^{\circ} \mathrm{C}\right)+\text { Area*Month }\end{array}$ \\
\hline 4 & $\begin{array}{l}\ln (C P U E+0.1 \text { meanCPUE })=\text { Year }(20)+\operatorname{Area}(7)+S \text { eason }(4)+S S T \\
\left(13,16^{\circ} \mathrm{C}-28^{\circ} \mathrm{C}\right)+\text { Area*Season }\end{array}$ \\
\hline 5 & $\begin{array}{l}\ln (\mathrm{CPUE}+0.1 \text { meanCPUE })=\text { Year }(20)+\text { Area }(4)+\text { Season }(4)+S S T \\
\left(13,16^{\circ} \mathrm{C}-28^{\circ} \mathrm{C}\right)+\text { Area*Season }\end{array}$ \\
\hline 6 & $\begin{array}{l}\ln (\mathrm{CPUE}+0.1 \text { meanCPUE })=\mathrm{Year}(20)+\mathrm{Area}(4)+\mathrm{S} \text { eason }(4)+\mathrm{SST} \\
\left(3,16^{\circ} \mathrm{C}, 21^{\circ} \mathrm{C}, 26^{\circ} \mathrm{C}\right)+\text { Area } * \text { Season }+ \text { Season*SST }\end{array}$ \\
\hline
\end{tabular}

1978) among the models. The formula of AIC is:

$$
\mathrm{AIC}=-2 \ln [\text { maximum likelihood }]+2 \mathrm{M},
$$

and can be reduced to:

$$
\mathrm{AIC}=\mathrm{X} \log (\mathrm{MSE})+2 \mathrm{Y},
$$




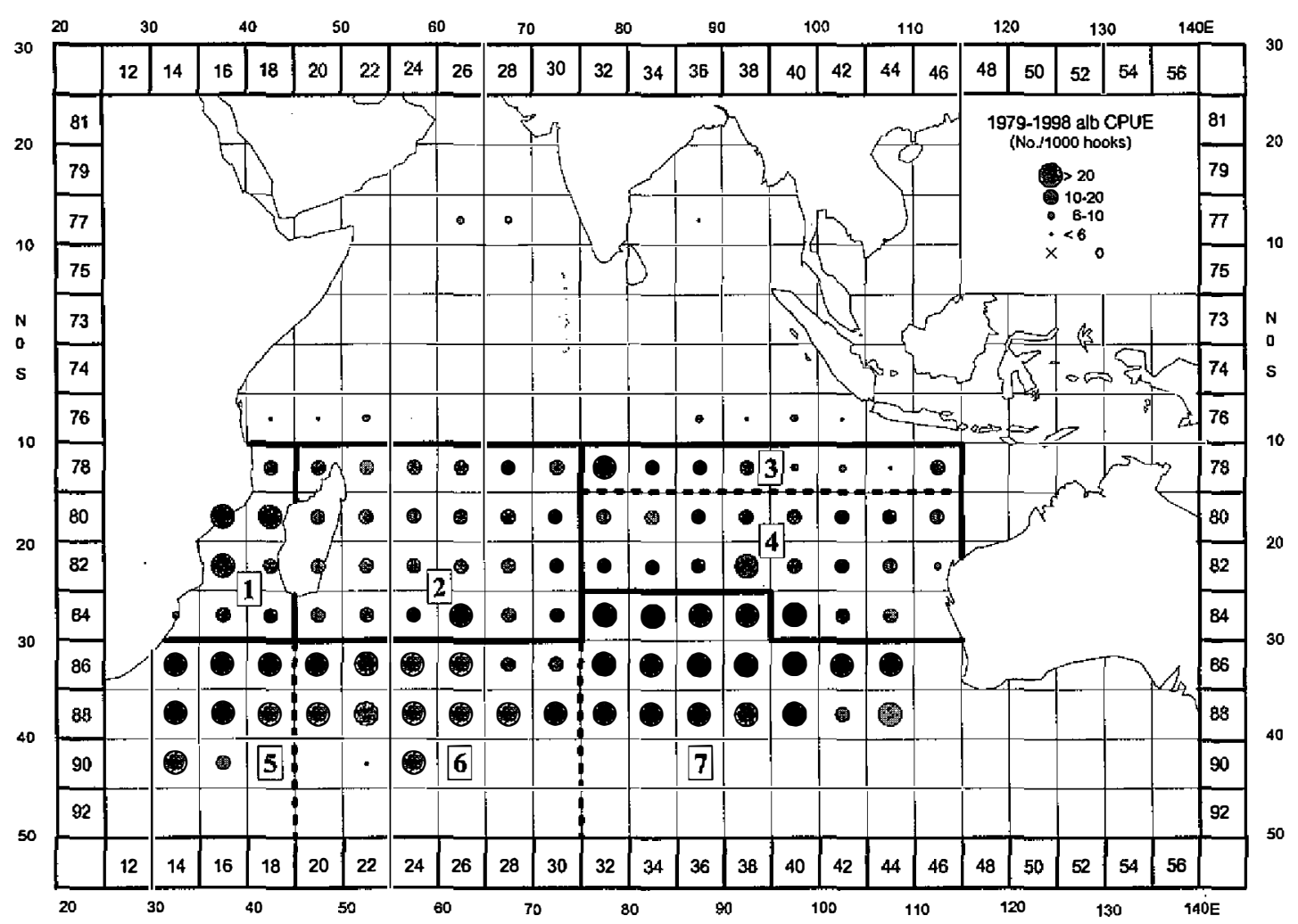

Fig. 1. The distribution of mean catch per unit effort averaging from 1979 to 1998 , and according to this distribution, the sub-area was stratified into 7 regions (as indicated by numerals) and 4 regions (combined sub-areas 3 and 4; and 5, 6 and 7), using in general linear models and for models comparison.

where $\mathrm{X}$ is the number of observations, MSE is the mean square error and $\mathrm{Y}$ is the number of parameters to be estimated. The model with the smallest AIC is selected as the best explanatory model. Thus, the GLM procedures in SAS software (Version 8.02) were used in the present study.

\subsection{Surplus Production Models Analysis}

The standardized CPUE selected from the estimation in the present study was used as the abundance index to fit surplus production models (Schaefer 1954; 1957; Fox 1974; 1975), then the maximum sustainable yield (MSY) and fishing effort to reach MSY $\left(f_{M S Y}\right)$ were estimated.

Two mathematical models for stock production analysis indicate that (1) Schaefer production model (Schaefer 1954; 1957): 


$$
U=\alpha f+\beta f^{2},
$$

and (2) Fox production model (Fox 1974; 1975):

$$
U=f e^{\alpha^{\prime}+\beta^{\prime} f},
$$

where $U$ is the standardized CPUE obtained in the present study, $\alpha$ and $\beta$ ( $\alpha^{\prime}$ and $\beta^{\prime}$ ) are two parameters to be estimated confronted the catch/effort data, and $f$ is the effective fishing effort, which for the $i$ th year was obtained from

$$
f_{i}=\frac{C_{i}}{U_{i}},
$$

where $C_{i}$ is the total annual catch for all gears in the $i$ th year and $U_{i}$ is the standardized CPUE in the $i$ th year.

Consequently, when the parameters $\alpha$ and $\beta\left(\alpha^{\prime}\right.$ and $\left.\beta^{\prime}\right)$ were estimated, the MSY and $f_{M S Y}$ were estimated respectively by: (1) for the Schaefer production model:

$$
\mathrm{MSY}=-\frac{\alpha^{2}}{4 \beta} \text { and } f_{M S Y}=-\frac{\alpha}{2 \beta} \text {, }
$$

and (2) for the Fox production model:

$$
\mathrm{MSY}=-\frac{1}{\beta^{\prime}} e^{\left(\alpha^{\prime}-1\right)} \text { and } f_{M S Y}=-\frac{1}{\beta} \text {. }
$$

\section{RESULTS}

\subsection{Catch, Effort and Catch per Unit Effort}

The catch compositions were illustrated in Fig. 2 for two different fishing types. The results indicate that the percent catch of albacore increased from 54.27 to $92.85 \%$, bigeye tuna catch decreased from 24.21 to $4.67 \%$, and yellowfin tuna catch decreased from 21.52 to $2.48 \%$ for the regular longline fishing type. On the contrary, the percent catch of albacore fell to 3 . $31 \%$, bigeye tuna increased to $49.98 \%$, and yellowfin tuna increased to $46.71 \%$ for the deep longline fishing type. The annual catch of Indian albacore by gears is illustrated in Fig. 3, which shows that two heavy exploitations were taken by gillnet from 1986 to 1991 and by longline from 1996 onward. For the biomass-based models used, a time series mean weight (catch in weight/catch in number) is estimated to convert CPUE in number into weight.

\subsection{Standardization of CPUE}

The results of goodness-of-fit of GLM were tested by the analysis of variance (ANOVA), 


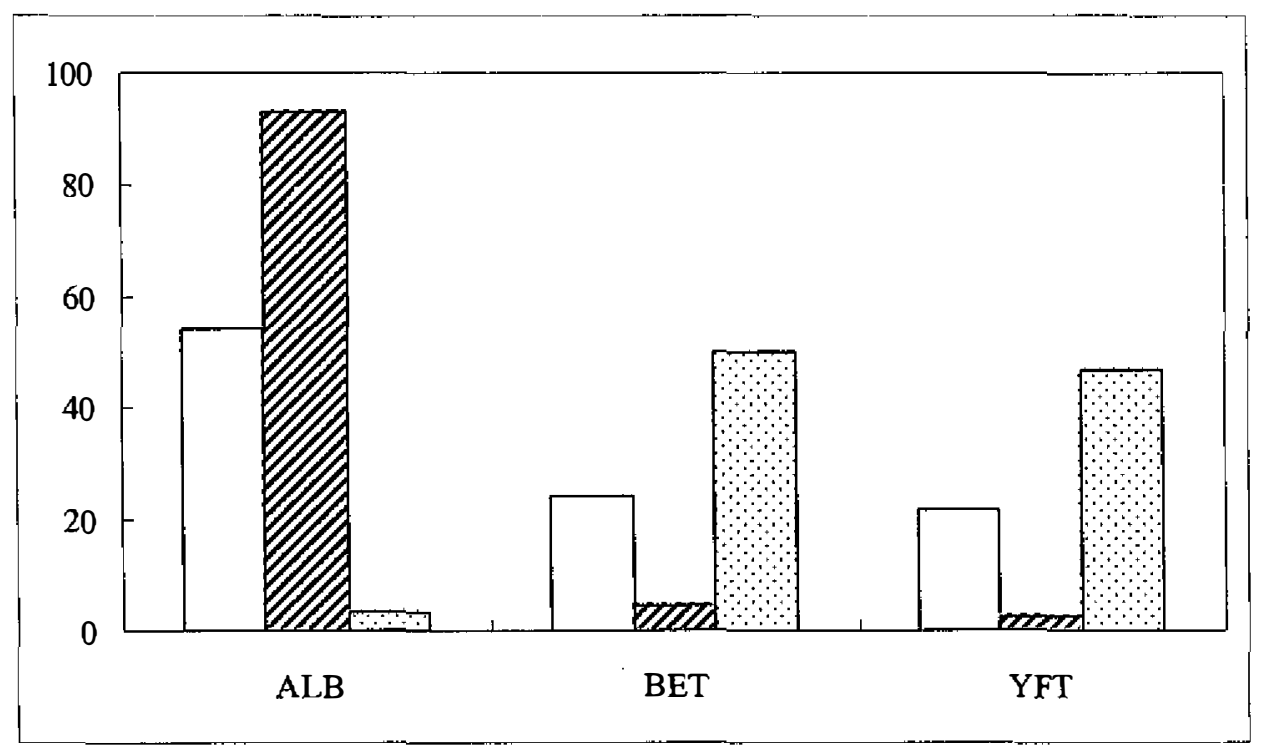

Fig. 2. Mean catch compositions (in percentage) of albacore, bigeye tuna and yellowfin tuna by different fishing types for Taiwanese longline fishery in the Indian Ocean, averaging from 1996-1998, in which blank bars denote the catch composition without partitioning fishing types; hatched and dotted bars represent the catch composition for regular and deep fishing types, respectively.

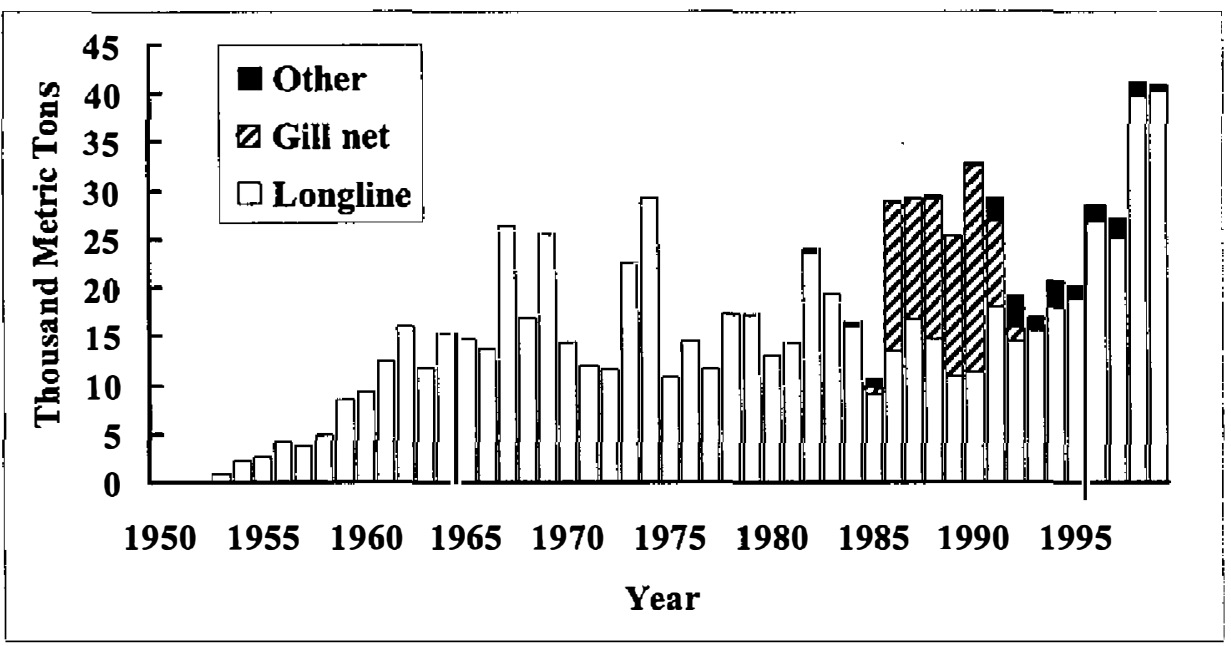

Fig. 3. Historical landings of albacore by longline, gillnet and other fisheries, of albacore in the Indian Ocean from 1953 to 1999. 
and all factors in all models (Table 1 ) were statistically significant $(\mathrm{P}<0.001)$. Among those models, the estimated values of AIC (Table 2) indicate that the model 2 is the best explanatory model in the present study. In addition, the frequency distribution of residuals of fitting the model 2 (Table 3 and Fig. 4) was analyzed to validate the error assumption, and the result of normality test by the Kolmogorov-Smirnov criterion (Sokal and Rohlf 1995) shows that the distribution of residuals is normal (Table 4, $\mathrm{D}=0.3047, \mathrm{P}<0.01$ ). Therefore, the GLM model 2 and its ANOVA table is given in Table 3, revealing that the year factor is the most important source resulting in abundance variation, and the SST factor is significant $(\mathrm{P}<0.001)$; however, this may not be as important as other factors due to its low contribution on variation in the present study.

Moreover, in order to investigate the effect of those significant factors in the model 2, the standardized CPUEs were investigated for each factor. Spatial changes of nominal and standardized CPUE are illustrated in Fig. 5, showing that the standardization scaled down the nominal CPUE, especially for sub-areas 5, 6 and 7 (Fig. 1) where the albacore were abundant. Fig. 6 indicates seasonal variation of nominal and standardized CPUE. The monthly standardized CPUE is stable except for those in July, November and December. Fig. 7 depicts the relationship between SST and nominal and standardized CPUE. The environmental factor of SST scaled largely down the nominal CPUE. The standardized CPUE on the SST indicated a slightly increasing trend from 16 to $19^{\circ} \mathrm{C}$, and then a gentle decrease.

And finally, the annual trend of nominal and standardized CPUEs was illustrated in Fig. 8. Regardless of the slight fluctuation, the annual standardized CPUE showed a decreasing trend from 1979 to 1992, and a slightly increasing trend from 1992 onward. The effective fishing effort was obtained according to equation (5), indicating that heavy fishing suffered from 1988 to 1991 when Taiwanese large-scaled gillnet fleets got involved in the fishery (Fig. 9), and the current effective fishing effort level (1998) was estimated as $252.8 \times 10^{6}$ hooks.

\subsection{Stock Assessment by Surplus Production Models Analysis}

Annual weight of catch for Taiwanese longline fishery, for which the abundance index is standardized, was illustrated in Fig. 10 from 1979 to 1998. The mean weight was used to convert standardized catch per unit effort in individual caught per 1,000 hooks into kg caught per 1,000 hooks. Then the relationship between total catch (in tones) and fishing effort was established by Schaefer and Fox production models, respectively without counting the yearclass strength (Fox 1975) from 1979 to 1998 (Fig. 11). The relationships obtained from fitting both models are highly significant $\left(R^{2}=0.632\right.$ for the Schaefer production model and $R^{2}=0$. 731 for the Fox production model, $\mathrm{P}<0.001$ ). The comparison between the standardized CPUE and the predicted CPUE is illustrated in Fig. 12, indicating that our estimation of two surplus production models can elucidate the trend of the study albacore stock.

Accordingly, the MSY and $f_{M S Y}$ were estimated according to equations (6) and (7), the results obtained are: (1) For Schaefer production model: MSY $=34,910$ metric tons, $f_{M S Y}$ $=296 \times 10^{6}$ hooks; and (2) for Fox production model: MSY $=32,168$ metric tons, and $f_{M S Y}=$ $313 \times 10^{6}$ hooks. 
Table 2. The results of Akaike's Information Criterion (AIC) computation using to select the most appropriate explanatory model fitted to standardize catch per unit effort of albacore in the Indian Ocean.

\begin{tabular}{cccccc}
\hline & $\begin{array}{c}\text { Number of } \\
\text { Models }\end{array}$ & Mean & Number of & & Ascending \\
& observatio & Square & parameters & AIC & order \\
& $n$ & Error & estimated & & \\
\hline 1 & 98142 & 0.30047 & 102 & -51046 & 2 \\
2 & 98142 & 0.29836 & 124 & -51302 & 1 \\
3 & 98142 & 0.30106 & 78 & -51010 & 3 \\
4 & 98142 & 0.30338 & 58 & -50723 & 4 \\
5 & 98142 & 0.30462 & 40 & -50585 & 5 \\
6 & 98142 & 0.30528 & 42 & -50489 & 6 \\
\hline
\end{tabular}

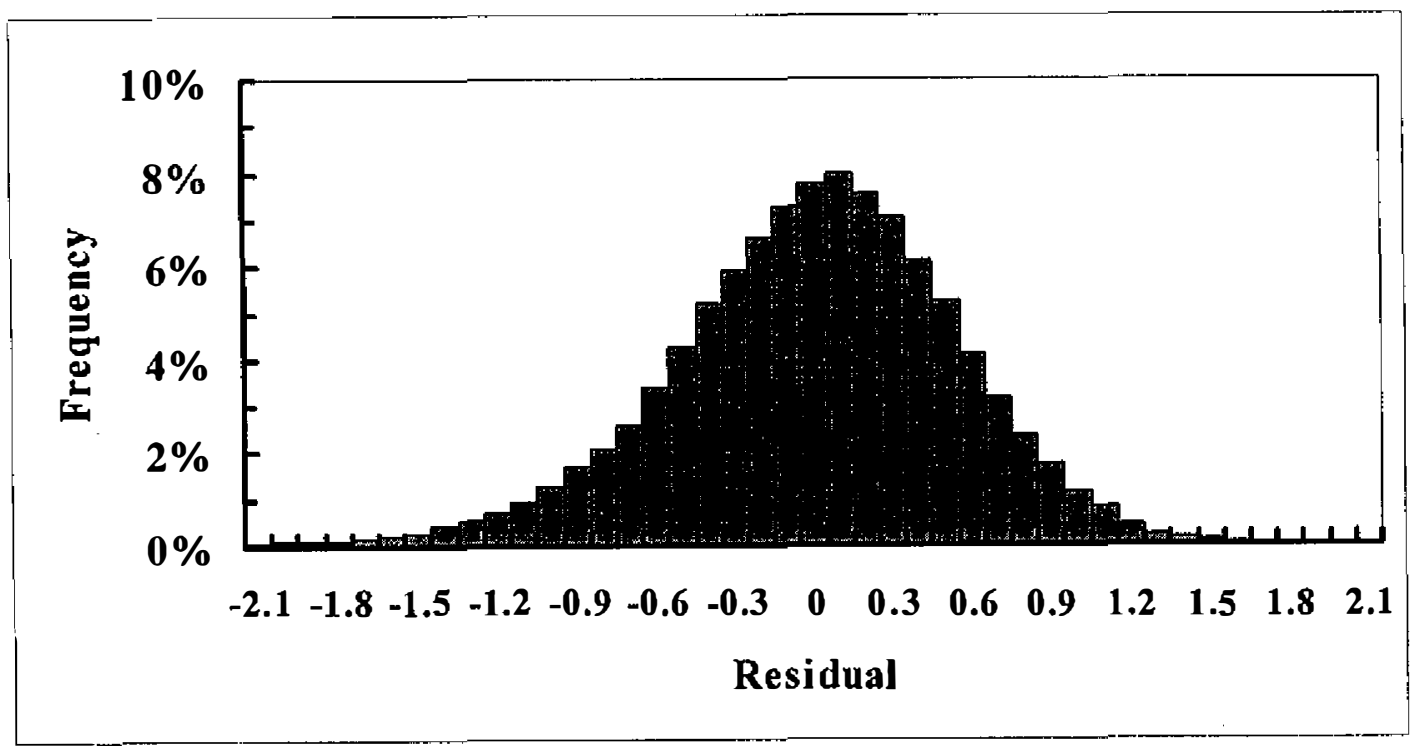

Fig. 4. The frequency distribution of residuals derived from general linear model, and the test statistic (Table 4) was used to prove the normal distribution assumption of errors. 
Table 3. The ANOVA table of GLM fitting for model 2 (Table 1).

\begin{tabular}{llll}
\hline \hline \multicolumn{1}{c}{ Class } & Levels & \multicolumn{1}{c}{ Values } \\
\hline Year & 20 & $1979-1998$ & \\
Area & 7 & 1234567 \\
Month & 12 & 123456789101112 \\
SST & 13 & 16171819202122232425262728 \\
\hline
\end{tabular}

\begin{tabular}{lrrrr}
\hline \multicolumn{1}{c}{ Source } & DF & Sun of Squares & Mean Square F Value & Pr $>$ F \\
\hline Model & 114 & 10139.1 & 88.9396 & $298.09<.0001$ \\
Error & 98027 & 29247.4 & 0.29836 & \\
Corrected Total & 98141 & 39386.5 & & \\
\hline
\end{tabular}

\begin{tabular}{cccc}
\hline R-Square & Coefficient of Variation & Root MSE & Log(cpue) Mean \\
\hline 0.25743 & 17.9688 & 0.546224 & 3.039842 \\
\hline
\end{tabular}

\begin{tabular}{lrrrrr}
\hline Source & DF & Type I SS & Mean Square & F Value & Pr $>$ F \\
\hline Year & 19 & 2925.07 & 153.951 & 515.99 & $<0.0001$ \\
Area & 6 & 6124.92 & 1020.820 & 3421.43 & $<0.0001$ \\
Month & 11 & 319.17 & 29.015 & 97.25 & $<0.0001$ \\
SST & 12 & 335.80 & 27.984 & 93.79 & $<0.0001$ \\
Area*Month & 66 & 434.14 & 6.578 & 22.05 & $<0.0001$ \\
\hline
\end{tabular}


(Table 3. Continued)

\begin{tabular}{lrrrrr}
\hline Source & DF & Type III SS & Mean Square & F Value & Pr $>$ F \\
\hline Year & 19 & 3466.86 & 182.466 & 611.56 & $<.0001$ \\
Area & 6 & 270.169 & 45.0282 & 150.92 & $<.0001$ \\
Month & 11 & 103 & 9.36364 & 31.38 & $<.0001$ \\
SST & 12 & 210.224 & 17.5187 & 58.72 & $<.0001$ \\
Area*Month & 66 & 434.141 & 6.57789 & 22.05 & $<.0001$ \\
\hline
\end{tabular}

Table 4. Moments and the normality test for the assumption of error structure used in the general linear model analysis which the Model 2 was applied on this standardization of abundance index.

Moments

\begin{tabular}{lr|lr}
\hline N (sample sizes) & 98142 & Sum Weights & 98142 \\
Mean & 0 & Sum Observations & 0 \\
Standard deviation & 0.5524 & Variance & 0.3051 \\
Skewness & -0.4328 & Kurtosis & 0.6642 \\
Uncorrected SS & 29947.2939 & Corrected SS & 29947.2939 \\
Coefficient variation & & Std Error mean & 0.001763 \\
\hline
\end{tabular}

Tests for Normality

\begin{tabular}{llcll}
\hline \multicolumn{1}{c}{ Test } & & Statistic & & p-value \\
\hline Kolmogorov-Smimov & $\mathrm{D}$ & 0.030477 & $\mathrm{Pr}>\mathrm{D}$ & $<0.0100$ \\
Cramer-von Mises & W-Sq & 30.25573 & $\mathrm{Pr}>\mathrm{W}-\mathrm{Sq}$ & $<0.0050$ \\
Anderson-Darling & A-Sq & 190.9799 & $\mathrm{Pr}>\mathrm{A}-\mathrm{Sq}$ & $<0.0050$ \\
\hline
\end{tabular}




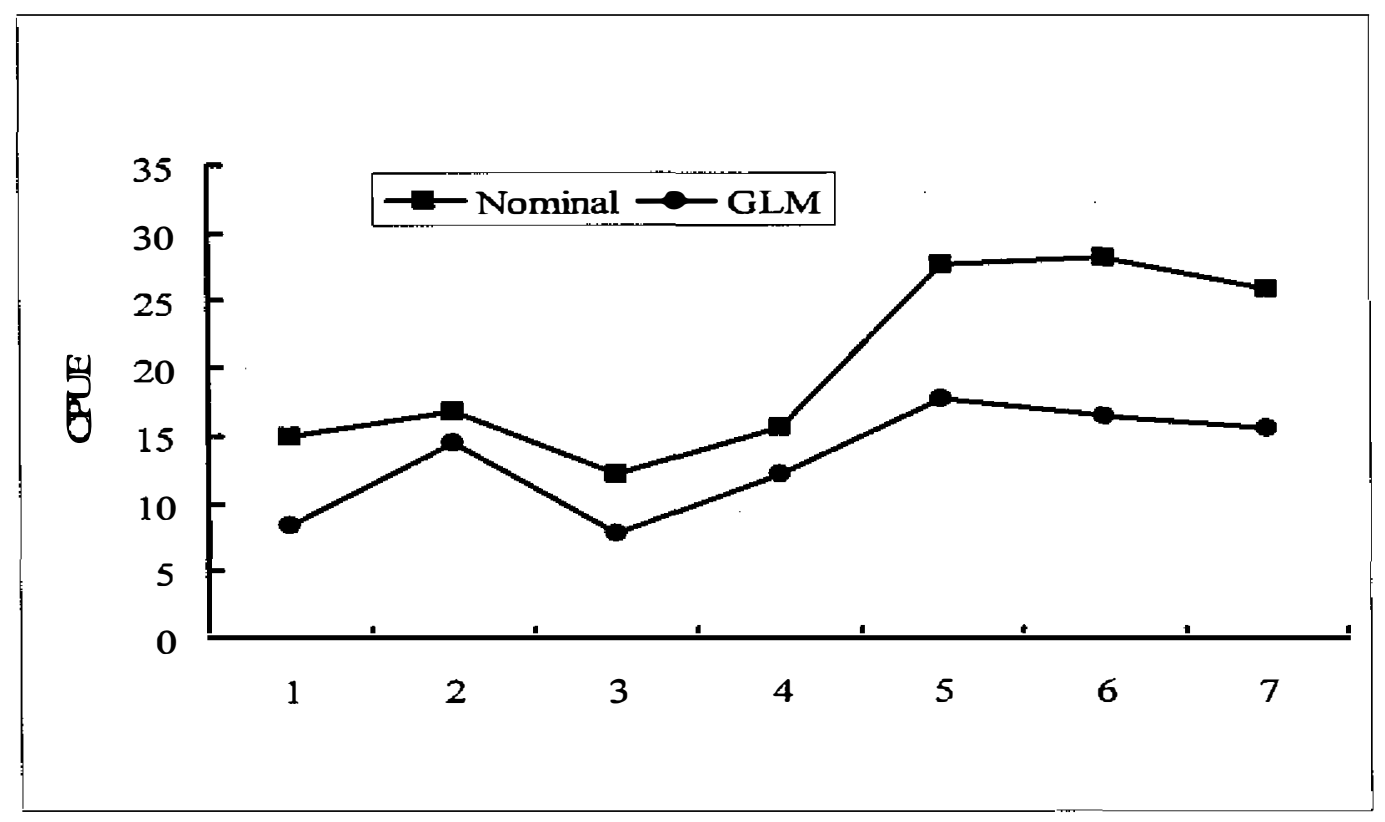

Fig. 5. Spatial variations of nominal and standardized (GLM) catch per unit effort of albacore in the Indian Ocean.

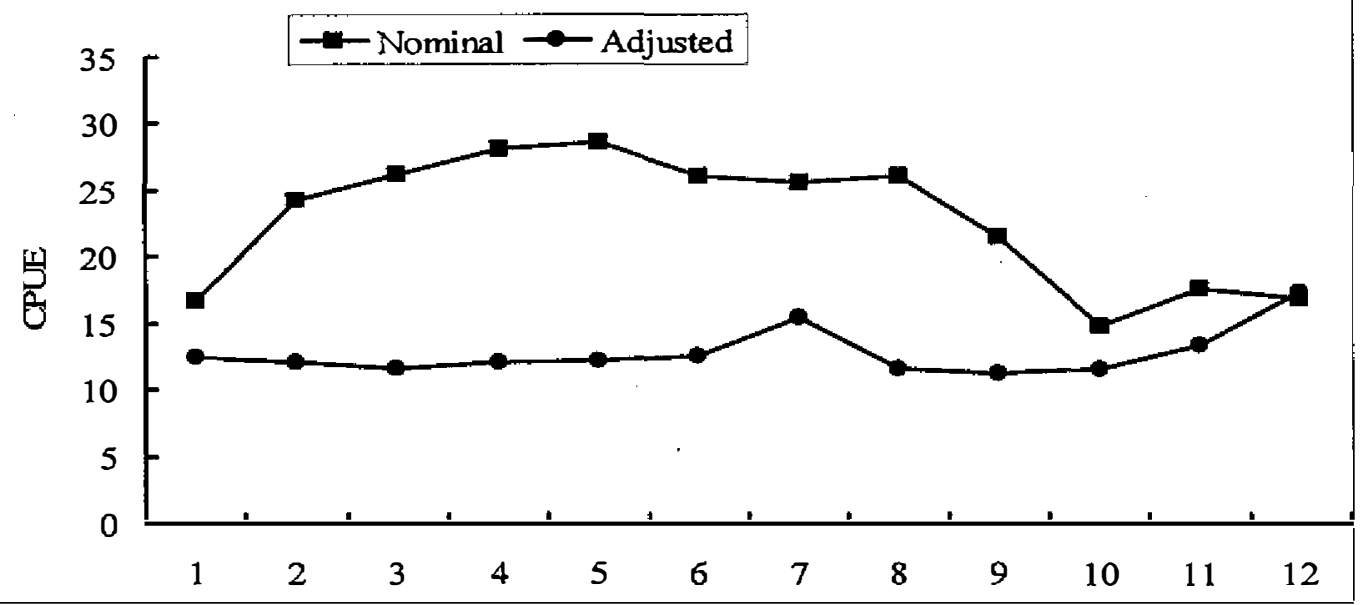

Fig. 6. Monthly changes of nominal and standardized (GLM) catch per unit effort of albacore in the Indian Ocean. 


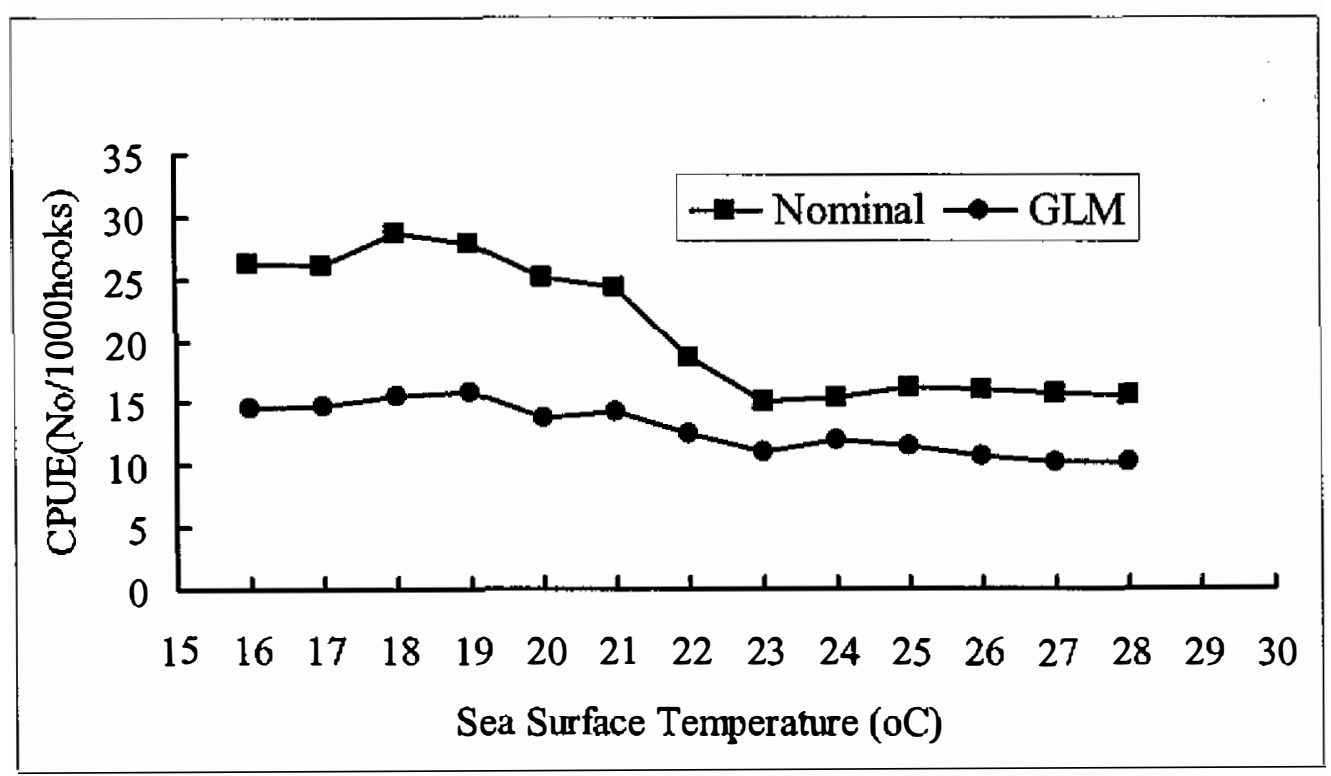

Fig. 7. Abundance indication of nominal and standardized (GLM) series by sea surface temperatures from $16^{\circ} \mathrm{C}$ to $28^{\circ} \mathrm{C}$ for albacore in the Indian Ocean.

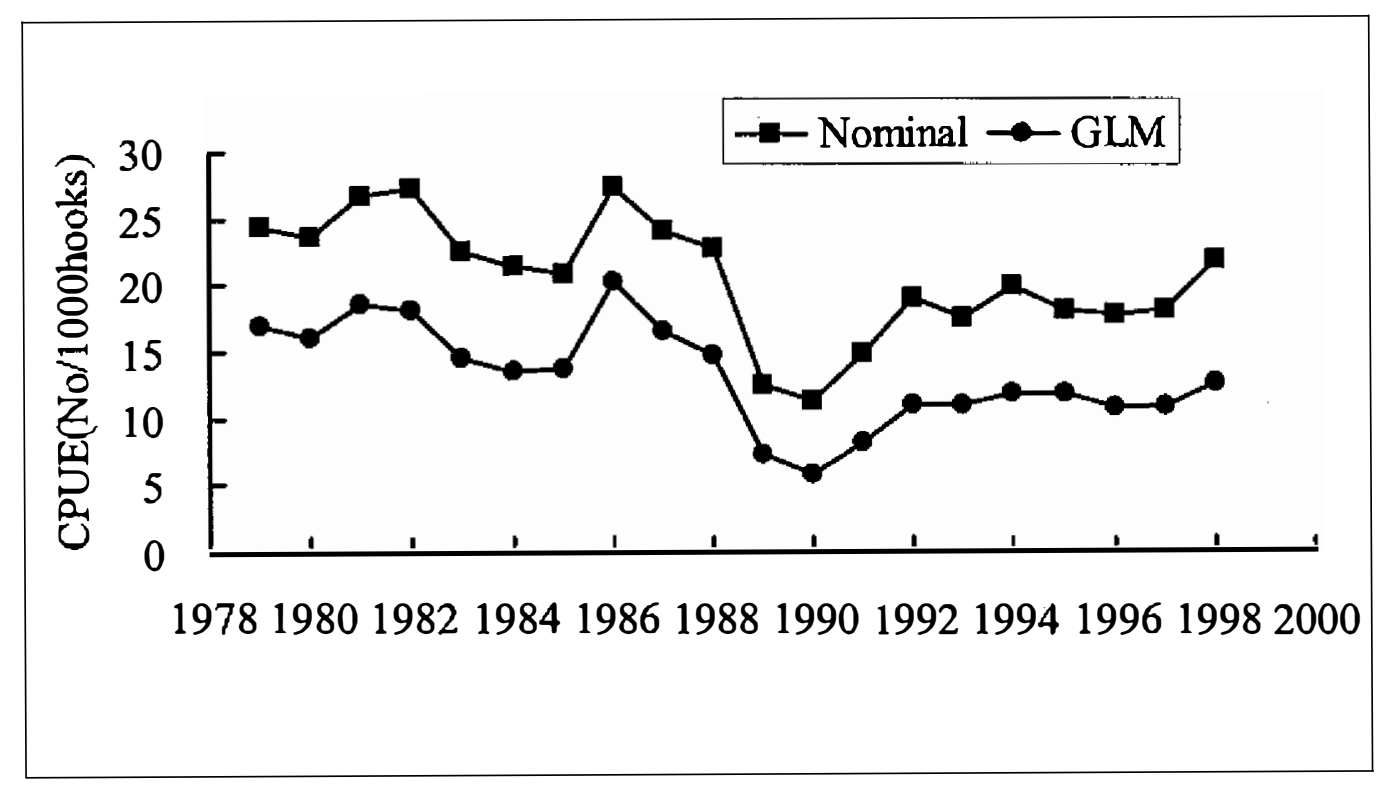

Fig. 8. Abundance indices of albacore stock in the Indian Ocean, represented by nominal catch per unit effort and standardized (GLM) catch per unit effort from 1979 to 1998. 


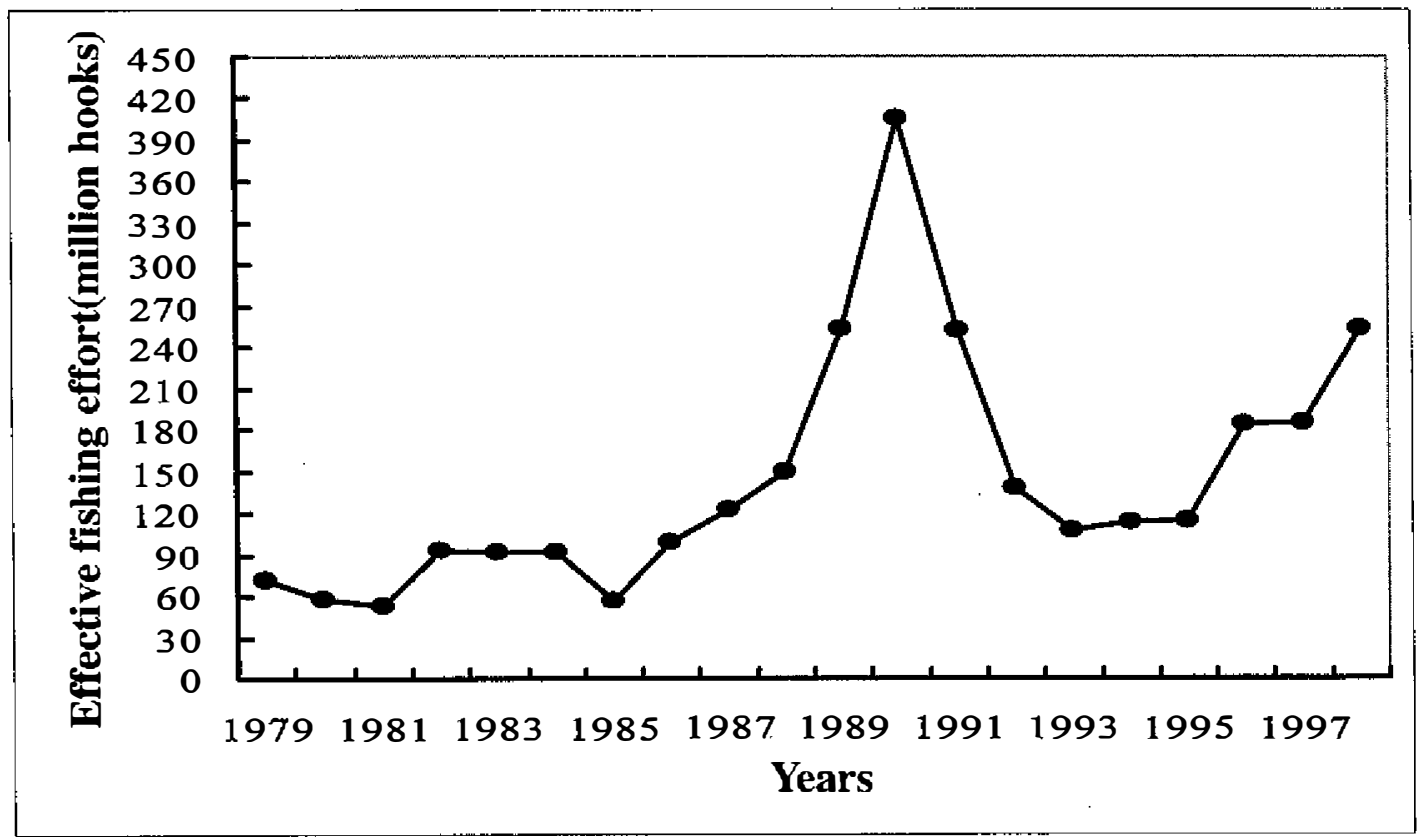

Fig. 9. The trajectory of effective fishing efforts estimated from total catch of albacore divided by standardized catch per unit effort in the Indian Ocean from 1979 to 1998.

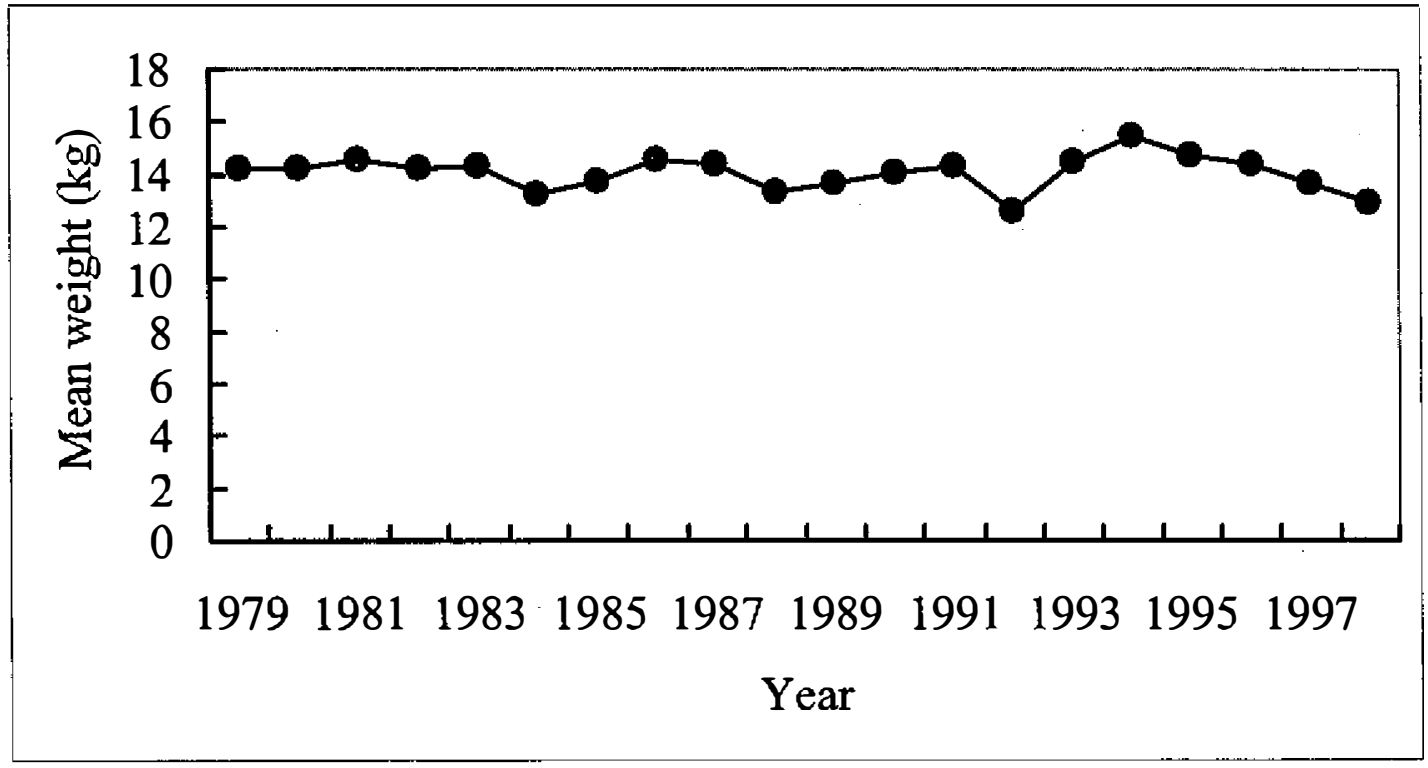

Fig. 10. Annual mean weight $(\mathrm{kg})$ of albacore caught by Taiwanese longline fishery in the Indian Ocean from 1979 to 1998. 


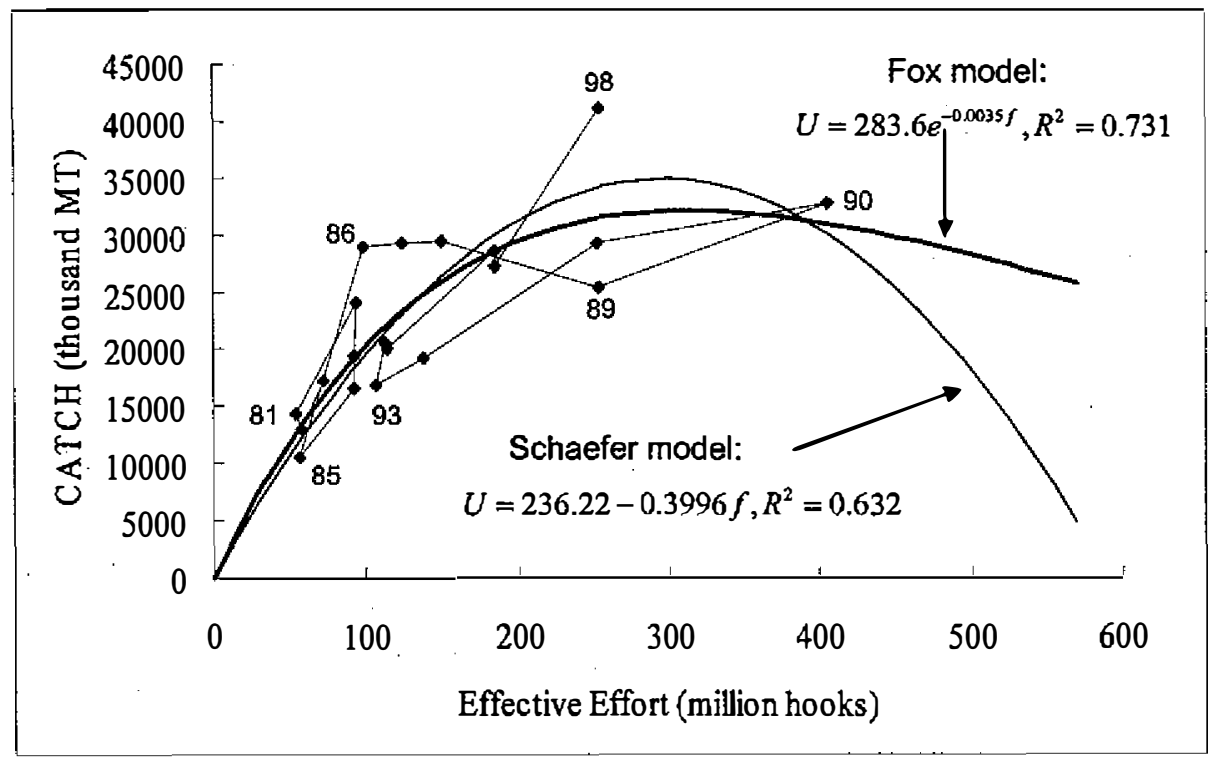

Fig. 11. The relationship of catch (metric tons) and effective fishing effort modeled by Schaefer and Fox production models to estimate maximum sustainable yield level and fishing effort for albacore stock.

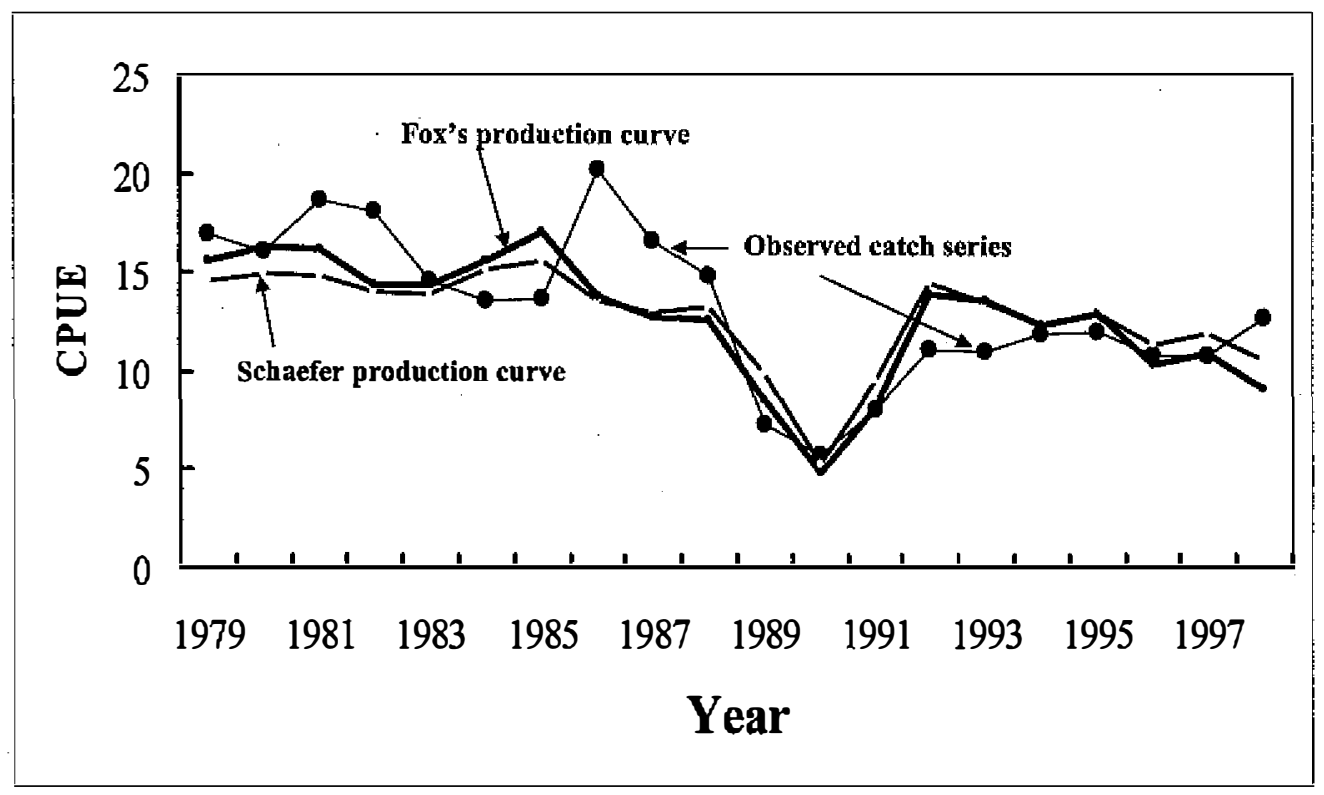

Fig. 12. Observed and two predicted CPUE time series to show that both the Fox's production model and the Schaefer production model are appropriate to describe the production of Indian albacore stock. 
Consequently, both results indicate that the albacore stock in the Indian Ocean is in healthy and fully exploited condition, and the current average catch level (25,600 metric tons averaging catch levels from 1994 to 1998), or even higher than this level, may be sustainable, although the 1998 catch level (41,156 metric tons) - which suffered an effective fishing effort ( $252.8 \times 10^{6}$ hooks) is lower than the estimated $f_{M S Y}$ - is the only year far higher than the estimated MSY during recent 8 years.

\section{DISCUSSION}

As expected, the current study has improved the abundance index estimation by segregating fishing types and incorporating sea surface temperature to standardize CPUE of albacore stock in the Indian Ocean. Accordingly, the population dynamics was reassessed as usually had been reported (Huang et al. 1986; Lee and Liu 1988; Shiohama 1988; Chang 1993; Hsu 1995). Inferring with catch (Fig. 3), fishing effort (Fig. 9) and CPUE series (Fig. 8), the current result of production models analyses (Fig. 11) apparently reveals that the stock is still in healthy and fully exploited status, though this stock suffered a heavy fishing pressure of gillnet in late 1980s (Hsu and Liu 1990) and longline since 1998 (Fig. 3). However, the 1998 catch level may not be sustainable for long-term exploiting this stock, so the fishery needs close monitoring.

To incorporate targeting problems into CPUE standardization, Lin (1998), and Hsu et al. (2001) have reported that the partitioning procedure is required in using Taiwanese longline catch-effort data to estimate abund ance index for albacore and tropical species, such as bigeye tuna and yellowfin tuna. Usually, categorizing the number of hooks between floats in the general linear model was pursued by quantile or percent (cf. Okamoto et al. 2001); however, this may not completely achieve the goal of standardizing CPUE, because to set a factor level using either quantile or percentage cannot adequately reflect the real attitude of longline fishing types.

Moreover, the environmental factor (sea surface temperature herein) was used for the first time in standardizing CPUE of albacore stock in the Indian Ocean. The result shows that this factor may not be as important as spatial and temporal factors, but its significant effect implies the importance of the factor. Chen (2000) and Marsac (2001) also reported the importance of climate and oceanographic condition on tuna distributions in the Indian Ocean. Lu et al. (1998) proved that the abundance of albacore is related to La Niño and Southem Oscillation Index. Those findings have strengthened and validated the necessitation of involvement of sea surface temperature in the present study. Our result is coincident with the finding that albacore is abundant with sea surface temperature from 15.6 to $19.4^{\circ} \mathrm{C}$ (Collete and Nauen 1983).

The geographical distribution is one of the most important factors used to standardize CPUE (Gulland 1965); thus, an appropriate division of fishing sub-areas is always employed for this purpose (cf. Honma 1974; Okamoto et al. 2001). The sub-area was stratified according to the nominal CPUE distribution in the present study (Fig. 1). The results show that more small fishing areas may obtain a more reasonable abundance index than a few large sub-areas, such as models 2 and 4 in comparison with models 3 and 5 (Table 1) in the present study.

Based on catch-effort data, the MSY estimation indicates that the fishery has been over 
fully exploited for some years. For Indian albacore stock, the annual catch levels peaked during 1986-1991 and 1996 onward, thus, the previous MSY estimates (Huang et al. 1986; Shiohama 1988; Chang 1993) ranging from 13,600 to 24,200 metric tons seem to be underestimates, because the catch-effort data used excluded the recent high catch levels, and the CPUE (Fig. 8) still increases as fishing effort increases (Fig. 9). In contrast, both used the same catch-effort time series data including those of 1998; thus, Wang et al. (2001b) have obtained an interval MSY estimation (27,200 27,700 metric tons) which is less than the MSY level estimated in this paper.

Therefore, it is likely that the abundance of albacore in the Indian Ocean has recovered under the heavy fishing by gillnet during 1988-1992, though the catch levels for those years are lower than the MSY level estimated here. Incorporating the consideration of fishing effort lower than $f_{M S Y}$, a possible high surplus productivity may result in the current catch levels of 1998 and 1999 (Fig. 3) being above 40,000 metric tons. Moreover, the abruptly increased catch is from longline fishery other than Taiwanese from 1998 (Anon. 2000), and the percentage of Indian albacore catch by Taiwanese longline fleets has been dropping to 55\% since 1998. In conclusion, the Indian albacore stock is in healthy and fully exploited status, but for long-term stock management and sustainable exploitation purposes, a very close monitoring and an intensive population dynamic study by advanced age-structured models are absolutely required soon for the near future.

Acknowledgements We thank referees' constructive comments on the improvement of the manuscript, especially a very useful concept for the general linear model used in the catch per unit effort standardization. We also appreciate the help of the tuna research laboratory staff, Institute of Oceanography, National Taiwan University in catch and effort data preparation.

\section{REFERENCES}

Akaike, H., 1973: Information theory and an extension of the maximum likelihood principle, In B. N. Petrov and F.Csaki(eds.), Proc. 2nd International Symposium on Information theory, pp. 267-281, Akademiai Kiado, Budapest.

Akaike, H., 1976: Canonical correlation analysis of time series and the use of an information criterion. In R. Mehra and D. G. Laniotis (eds.), System identification: Advance and case studies. Academic Press, New York.

Akaike, H., 1978: A Bayesian analysis of minimum AIC procedure. Annuals of Institution of Statistical and Mathematics, 30A, 9-14.

Allen, R. L., and R. G. Punsly, 1984: Catch rates as indices of abundance of yellowfin tuna, Thunnus albacares, in the eastern Pacific Ocean. Bulletin, Inter-American Tropical Tuna Commission, 18(4), 301-379.

Anon., 2000: Indian Ocean tuna fisheries data summary, 1989-1998. Indian Ocean Tuna Commission, Data Summary No. 20, 108pp.

Campbell, R. A., G. Tuck, S. Tsuji, and T. Nishida, 1996: Indices of abundance for southern bluefin tuna from analysis of fine-scale catch and effort data. Southern Blufin Tuna Working Series, 96, 35p. 
Chang, S. K., 1993: Stock assessment on Indian Albacore using nonequilibrium production model. Ph. D. Thesis, Institute of Oceanography, National Taiwan University, Taipei, Taiwan, 89pp.

Chang, S. K., C. C. Hsu, and H. C. Liu, 2001: Management implication on Indian albacore from simple yield analysis incorporating parameter uncertainty. Fish. Res., 51, 1-10.

Chen, I. C., 2000: Fishing ground of the Indian albacore (Thunnus alalunga) and its relationship with environment factors. MS Thesis, Department of Zoology, National Taiwan University, Taipei., 87pp.

Collette, B. B., and C. E. Nauen, 1983: FAO species catalogue. Vol. 2. Scombrids of the world. An annotated and illustrated catalogue of tunas, mackerels, bonitos and related species known to date. FAO Fish Synopsis 125., 2, 137 pp.

Francis, R. C., 1974: Effects of fishing modes on estimates of fishing power, relative abundance and surplus production in the eastern Pacific yellowfin tuna fishery. International Commission for the Conservation of Atlantic Tunas, Collective Volume of Scientific Papers, 3, 194-211.

Fox, W. W., 1974: An exponential surplus-yield model for optimizing exploited fish populations. Transaction of American Fisheries Society, 1, 81-88.

Fox, W. W. Jr., 1975: Fitting the generalized stock production model by least-squares and equilibrium approximation. Fishery Bulletin, 73(1), 23-37.

Gulland, J. A., 1965: Estimation of mortality rates. Annex to Arctic Fisheries Workshop Group Report. International Council for Exploitation of the Seas CM1965, Doc. 3. Mimeo, Copenhagen.

Hinton, M. G., and H. Nakano, 1996: Standardizing catch and effort statistics using physiological, ecological, or behavioral constraints and environmental data, with an application to blue marlin (Makaira nigricans) catch and effort data from Japanese longline fisheries in the Pacific. Bulletin, Inter-American Tropical Tuna Commission, 21(4), 171-200.

Honma, M., 1974: Estimation of overall effective fishing intensity of tuna longline fishery. Bulletin of Far Seas Fisheries Research Laboratory, 10, 63-85.

Hsu, C. C., 1995: Stock assessment of albacore in the Indian Ocean by age-structured production model. Journal Fisheries Society of Taiwan, 22(1), 1-13.

Hsu, C. C., 2002: On the dynamics of albacore population in the Indian Ocean. J. Fish. Soc. Taiwan, 29(2), 85-105.

Hsu, C. C., and H. C. Liu, 1990: Taiwanese longline and gillnet fisheries in the Indian. IndoPacific Tuna Development and Management, Collective Volume of Working Documents, 4, 244-258.

Hsu, C. C., H. H. Lee, Y. M. Yeh, and H. C. Liu, 2001: On targeting problem, partitioning fishing effort and estimating abundance index of bigeye tuna for Taiwanese longline fishery in the Indian Ocean. Proceedings of the Third Working Parties of Tropical Tunas, Indian Ocean Tuna Commission, June 19-27, 2001. Seychelles.

Huang, F. T., C. H. Wang, and H. C. Liu, 1986: Estimation of overall fishing intensity and stock assessment of Indian Ocean albacore(Thunnus alalunga), 1963-1984. FAO IPTP TWS/86/34. 
Lee, Y. C., and H. C. Liu, 1988: Estimation of effective fishing effort and overall fishing intensity and stock assessment of Indian Ocean albacore (Thunnus alalunga), 19621986. FAO IPTP TWS/88/62.

Lee, Y. C., and H. C. Liu, 1995: An updated virtual population analysis of the Indian Ocean albacore stock. 1980-1992. In: J. D. Ardill, Ed. 1996, Proceedings of the Sixth Expert Consultation on Indian Ocean Tunas, 9, 267-278.

Lin, C. J., 1998: The relationship between longline fishing patterns and catch composition in the Indian Ocean. Ms. Thesis, Institute of Oceanography, National Taiwan University, Taipei. 57pp.

Lu, H. J., K. T. Lee, and C. H. Liao, 1998: On the relationship between El Nino/southern Oscillation and South Pacific albacore. Fisheries Research, 39, 1-7.

Marsac, F., 2001: Climate and oceanographic indices appraising the environmental fluctuation in the Indian Ocean. Proceedings of the Third Working Parties of Tropical Tunas, Indian Ocean Tuna Commission, June 19-27, 2001. Seychelles.

O'Brien, C. M., and L. T. Kell, 1997: The used generalized linear models for the modeling of catch-effort series. I. Theory. International Commission for the Conservation of Atlantic Tunas, Collective Volume of Scientific Papers, 46(4), 476-482.

Okamoto, H., N. Miyabe, and T. Matsumoto, 2001: GLM analysis for standardization of Japanese longline CPUE for bigeye tuna in the Indian Ocean applying environmental factors. Proceedings of the Third Working Parties of Tropical Tunas, Indian Ocean Tuna Commission, June 19-27, 2001. Seychelles.

Punsly, R. G., 1987: Estimation of the relative annual abundance of yellowfin tuna, Thunnus albacares, in the eastern Pacific Ocean during 1970-1985. Bulletin, Inter-American Tropical Tuna Commission, 19(3), 265-306.

Robson, D. S., 1966: Estimation of relative fishing power of individual ships. Research Bulletin, International Commission of Northwest Atlantic Fisheries, 3, 5-14.

Schaefer, M. B., 1954: Some aspects of the dynamics of population important to the management of the commercial marine fisheries. Bulletin, Inter-American Tropical Tuna Commission, 1(2), 26-56.

Schaefer, M. B., 1957: A study of the dynamics of the fishery for yellowfin tuna in the eastern tropical Pacific Ocean. Bulletin, Inter-American Tropical Tuna Commission, 2(6), 245285.

Shiohama, T., 1988: Stock assessment of Indian Ocean albacore, 1988. FAO IPTP TWS/88/ 42.

Sokal, R. R., and F. J. Rohlf, 1995: Biometry, 3rd edition. W. H. Freeman Company, New York.

Uozumi, Y., 1993: The CPUE trend for albacore in Indian Ocean waters caught by the Japanese longline fishery, pp.147-149. In: J. D. Ardill, ed, 1994, Proceedings of the 5th Expert Consultation on Indian Tunas, 275pp.

Wang, S. H., C. C. Hsu, and H. C. Liu, 2001a: Using fuzzy synthesis approach to extract fishing efforts directed on albacore for Taiwanese longline fleets in the Indian Ocean. J. Fish. Soc. Taiwan, 28(2), 36-49.

Wang, S. H., C. C. Hsu, and H. C. Liu, 2001b: A new assessment approach using fuzzy 
surplus production model to evaluate the albacore stock in the Indian Ocean. Journal of the Fisheries Society of Taiwan, 28(4), 329-338. 